\title{
Thermal Performance of a Heat Pipe with Different Working Fluids
}

\author{
Ayad Alwaer ${ }^{* 1}$, Jasson Gryzagoridis ${ }^{2}$ \\ ${ }^{1}$ Department of Renewable Energies, Higher Institute of Science and Technology, Tarhuna, Libya \\ ${ }^{2}$ Department of Mechanical Engineering, College of Engineering, Cape Peninsula University of \\ Technology, Cape Town South Africa
}

DOI: https://doi.org/10.21467/proceedings.4.5

* Corresponding author email: GryzagoridisJ@cput.ac.za

\begin{abstract}
The use of Heat pipes, for a variety of applications, has increased worldwide due to them achieving high thermal efficiencies. Heat pipes in evacuated tube solar collector systems, in modern domestic water heating, comprise of a sealed envelope of a copper pipe, which contain a small quantity of working fluid. The Heat pipe transfers energy by the latent heat of the evaporation of the working fluid in a heating section. This vapor travels to the cold portion of the heat pipe and condenses. The circulation is completed with the condensate flowing back through the container's inner wall to the heating section by gravity. Tests were conducted using a test apparatus specifically made for the purpose of comparing the relevant attribute of thermal performance of Heat pipes containing different working fluids. A commercially available heat pipe, with its proprietary working fluid, was used as a reference in comparing its thermal performance efficiency $(57.1 \%)$ with those of identical heat pipes containing distilled water, methanol, acetone and ethanol as working fluids. The results from the experiments achieved thermal efficiencies of $63.1 \%, 60.5 \%, 57.6 \%$, and $42.1 \%$ respectively.
\end{abstract}

Keywords: Heat pipe technology; working fluid; efficiency; solar energy; evacuated glass heat pipe collector

\section{Introduction}

The evacuated tube consists of an outer and inner glass tube with a vacuum trapped between these glass sections. This allows for radiation to penetrate into a centrally located heat pipe, but prevents heat loss via dissipation. The heat pipe is located centrally inside the inner tube. The heat pipe normally consists of a long copper tube containing a very small quantity of the working fluid (e.g., water, acetone, methanol, ethanol, etc.) which forms the vehicle for moving heat to the cooler section of the copper tube. Each collector is made up of a frame, a manifold and a set of tubes -either 8,12,18 or 24 tubes, depending upon the geyser size.

There are various forms of heat pipes, which are commercially used in the solar collector panels. As shown in Figure 1, the structure is basically very similar with variations in the shape and size of the (upper portion) condenser [1,2].

\footnotetext{
(C) 2018 Copyright held by the author(s). Published by AIJR Publisher in Proceedings of First Conference for Engineering Sciences and Technology (CEST-2018), September 25-27, 2018, vol. 2.

Sciences and Technology (CEST-2018), September 25-27, 2018, vol. 2 .
This is an open access article under Creative Commons Attribution-NonCommercial 4.0 International (CC BY-NC 4.0)

AijR license, which permits any non-commercial use, distribution, adaptation, and reproduction in any medium, as long as the original work is properly cited. ISBN: 978-81-936820-6-7
} 


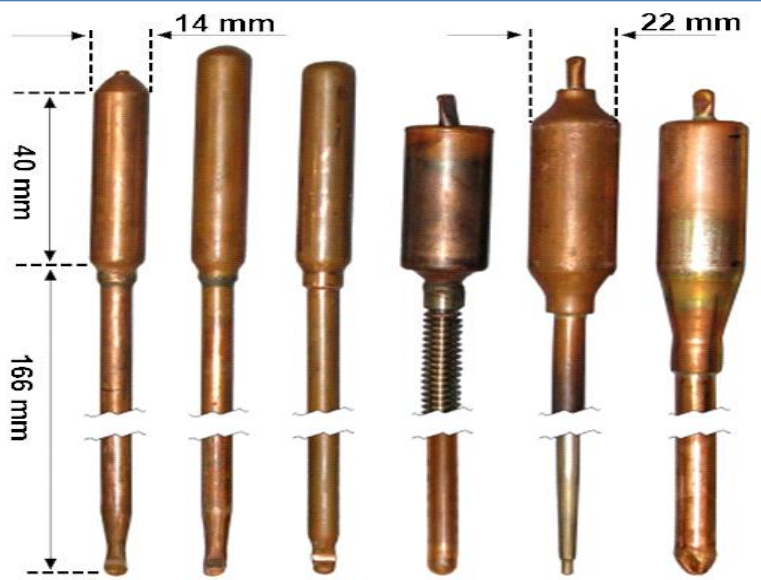

Figure 1: Various geometrical forms of heat pipes [1]

\section{Heat Pipe Structure and Operation}

The design of the heat pipe includes a long copper pipe with a larger diameter condenser at the top and welded at the other end. A small amount of working fluid is added into the heat pipe and then heated to high temperature, or a vacuum pump is used to remove the air from within the space. The result of either method is a vacuum in the copper pipe [3].

The vacuum inside the heat pipe allows the phase change of the fluid to a gas to occur at a lower temperature. The reason for this is to expedite the heat transfer process and create the continuous heat transfer cycle $[4,5 \& 6]$

The evacuated tube heat pipes typically found in solar collectors containing a small amount of working fluid have a boiling point of around 25 degrees Celsius as a result of the induced vacuum, so when heating the heat pipe above this temperature the working fluid begins to evaporate. The vapour rises to the condenser at the top of the heat pipe, where it condenses (giving off heat to the desired spot) and returns to the evaporation section at the bottom of the heat pipe. This process is repeated as a cycle $[4,5 \& 7]$.

\subsection{The Working Fluid}

As stated before, the heat pipes can utilise various liquids as a working medium. Table 1 refers to the relevant properties of typical fluids that could be used.

Table 1: Physical properties of Some Heat pipe working fluids $[8,9]$.

\begin{tabular}{|l|c|c|c|c|c|c|}
\hline Fluid & NBP $\left({ }^{\circ} \mathrm{C}\right)$ & $\varrho(\mathrm{kg} / \mathrm{m} 3)$ & Psat* $(\mathrm{kPa})$ & $\mu^{* *}(\mathrm{~kg} / \mathrm{ms})$ & $\sigma^{* *}(\mathrm{~N} / \mathrm{m})$ & $\lambda(\mathrm{kJ} / \mathrm{kg})$ \\
\hline Water & 100 & 1000 & 2.33 & $1.79 \times 10^{-3}$ & $7.56 \times 10^{-2}$ & 2256 \\
\hline Ethanol & 78 & 789 & 5.95 & $1.77 \times 10^{-3}$ & $2.41 \times 10^{-2}$ & 846 \\
\hline Methanol & 65 & 792 & 13.02 & $8.17 \times 10^{-3}$ & $2.45 \times 10^{-3}$ & 1100 \\
\hline Acetone & 56 & 784 & 30 & $4.1 \times 10^{-4}$ & $2.4 \times 10^{-2}$ & 518 \\
\hline
\end{tabular}

* The vapor pressure data are at $293{ }^{\circ} \mathrm{K}$., $20^{\circ} \mathrm{C}$

** Surface tension and viscosity data are at $273^{\circ} \mathrm{K}$., $0^{\circ} \mathrm{C}$ 
Some working fluids need a compatible vessel material to prevent and avoid chemical reactions or corrosion between the fluid used and the vessel. Chemical effects such as corrosion reduce the efficiency of the vessel, as a non-condensable gas can be produced by chemical reactions. For example, using ammonia as a working fluid in the heat pipe provides a temperature range from -70 to $+60{ }^{\circ} \mathrm{C}$ and is compatible with several vessel materials such as aluminum, nickel and stainless steel, but not copper [10]. In selecting a working fluid for use in a heat pipe application, the prime requirements are as follows, [11].

- Good thermal stability.

- Vapor pressures not too high or low over the operating temperature range.

- High latent heat.

- High thermal conductivity.

- Low liquid and vapor viscosities.

- Acceptable freezing or pour point.

The viscosity, sonic, capillary, entrainment and nucleate boiling limitations play important roles when selecting the working fluid $[4,5 \& 6]$. However, in the context of this research, the choice of the working fluid in the heat pipe will rest solely on the level of temperature achieved in the condenser part of the heat pipe. The reason adopted here is that this factor will govern the amount of heat that the heat pipe could transfer. In other words, the higher temperatures at the condenser will inherently be able to transfer more heat (comparatively speaking among heat pipes containing different working fluids) to the bulk of the fluid that is being heated. Therefore, internal heat pipe criteria such as the viscous limit, the sonic limit, the entrainment limit affecting the maximum heat flux, the capillary limit, etc., will be ignored and, the recommendation of which working fluid will best enhance the performance of the commercial evacuated heat pipe solar collector will depend entirely on calorific results [11, 12\&13].

\subsection{Energy Performance Analysis in the Heat Pipe Testing Apparatus}

The energy performance indices to be obtained using a specially designed and constructed apparatus in this part of the study, will entail the energy collected from the sun simulator via the heat (using different working fluids) to equal the energy transferred by the heat pipe to the water in the apparatus's tank. In other words the efficiency of the heat pipe can be calculated in terms of heat transfer associated with the change of the internal energy of the water in the system. The heat input will be controlled using a solar simulator and the ambient temperature is not expected to change appreciably since the testing will be done in a laboratory.

\subsection{Efficiency of Heat Pipe in Terms of Heat Transfer to Tank's Water}

The efficiency of the heat pipe is calculated using the following formula, which involves the change of the internal energy of the water contained in the system's tank.

Proceedings of First Conference for Engineering Sciences and Technology (CEST-2018), vol. 2 


$$
\eta_{h p}=\frac{\left(\Delta Q_{u}\right) / t}{I} m \times 100 \%
$$

Where $\eta_{h p}$ is the heat pipe's efficiency (\%) in terms of heat transfer to the tank's water, $\Delta Q_{u}$ is the change in the internal energy of the water in $\mathrm{kJ} / \mathrm{kg}$ which is dependent on the temperature $T$ and pressure $P$ of the system, $t$ is the solar irradiance time in hours, $m$ is the mass in $\mathrm{kg}$ of water in the tank and $I$ is the actual total solar radiation on the surface of the evacuated tube heat pipe, which is the irradiance $\mathrm{kW} / \mathrm{m}^{2}$ from the solar simulator multiplied by the heat pipe's actual receiving area of $\left(0.08084 \mathrm{~m}^{2}\right)$.

\section{A Rig for Testing the Performance of the Heat Pipe with Various Working Fluids}

In order to test the performance of the heat pipe with various working fluids, an apparatus was designed and constructed consisting of a small geyser tank mounted on a frame. A heat pipe with its evacuated glass tube could easily be inserted and removed in a short turnaround time (see Figures 2 and 3). A single evacuated heat pipe assembly could be inserted in a dry bay attached to a tank which could accommodate four litters of water. Halogen floodlights mounted on a frame over the heat pipe assembly provided the heat source.
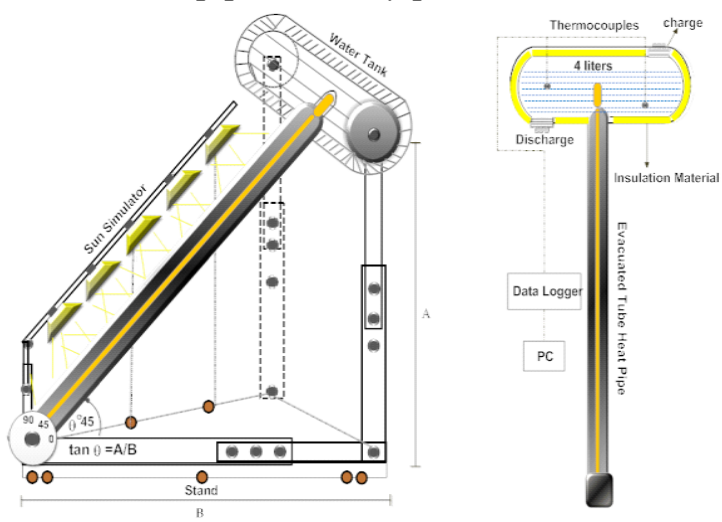

Figure 2: Schematic diagram of the testing apparatus for the heat pipes.

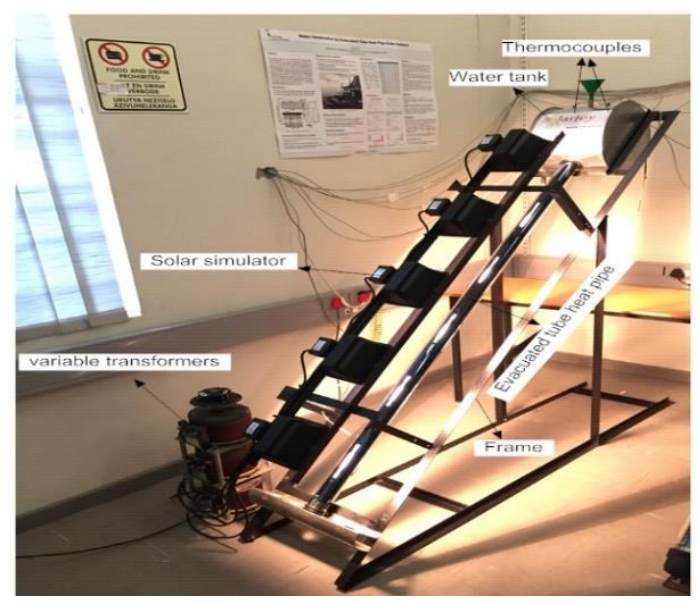

Figure 3: The heat pipe's testing apparatus 


\subsection{Tank Description}

The cylindrical tank was made of $1.2 \mathrm{~mm}$ thick stainless steel sheet; with dimensions of 200 dia. and $150 \mathrm{~mm}$ long. An outer casing was built around the tank to cover the polyurethane insulation.

A brass heat pipe sleeve (14 $\mathrm{mm}$ internal diameter) was welded into the tank at a 45 degree angle to line up with the mounting frame of the heat pipe, tank and simulator.

In addition, two wells were built into the top of the tank to place thermo-couple sensors in order to record the temperature of the top and bottom fluid levels in the tank respectively. On the side of the tank a valve drain pipe was fitted with a $15 \mathrm{~mm}$ filling pipe fitted at the top. The halogen lights were controlled via a variable transformer thus regulating the simulated radiation on the heat pipe.

\subsection{The Sun Simulator for the Heat Pipe Tester}

The solar radiation simulator was used to heat the evacuated heat pipe. It consisted of an array of five halogen floodlights of $500 \mathrm{~W}$ each. The halogen lamps were distributed evenly over the length of the evacuated tube heat pipe, at a distance of $225 \mathrm{~mm}$ above it. The solar simulator's irradiance level was set to a level consistent with an average 800 watts per square metre, as measured over the evacuated heat pipe surface. The output of the sun simulator could be controlled by means of a variac (variable transformer) which controlled voltage supplied to the array of halogen lamps.

\subsection{Frame}

The frame was built using $\mathrm{L}$ shape mild carbon steel sections set for testing at a fixed angle of 45 degree.

\section{Instrumentation for the Heat Pipe Tests}

Two J-type thermocouples, one of them at the bottom and another at the top of the "geyser", were fitted to measure the water temperature in the storage tank, and, together with the ambient temperature, were recorded during the test period. A digital display data logger (Agilent-34972A) was used to record the temperature scale. All experiments were carried out for seven hours.

\section{Testing the Heat Pipe Performance with Different Working Fluids.}

The relatively elevated temperatures which are obtainable when using evacuated tube heat pipes in the field of water heating is the reason for the attempt to use them in the desalination of seawater.

The method followed in testing a set of working fluids in the heat pipe is described below:

Proceedings of First Conference for Engineering Sciences and Technology (CEST-2018), vol. 2 
Thermal Performance of a Heat Pipe with Different Working Fluids

Testing of the heat pipe's performance with various working fluids required a benchmark. This benchmark was obtained by first testing the commercial heat pipe (as it came from the manufacturer) with the original working fluid. Attempts to obtain information about the constitution of the working fluid, from the manufacturer in China, were unsuccessful. It was assumed that the liquid was water, but it had an orange/yellowish colour possibly because of some kind of additive. The fluid was drained and the heat pipe was charged with new fluid, after which the performance test was undertaken over the seven-hour period. It is worth mentioning here that the quantity of working fluid encountered in the commercial heat pipes varied considerably in the range of 5 to $10 \mathrm{ml}$; however this did not seem to affect their performance.

The raw data that was collected during each heat pipe experiment with the four working fluids consisted of recording the temperatures of the water at two locations in the tank's water, the irradiance from the solar simulator and the ambient temperature Ta. The duration of the individual tests was seven consecutive hours daily. The data displayed in Appendix A is a typical sample, where $T_{1} \& T_{2}$ are the tank's water temperatures (in degrees centigrade) recorded every 15 minutes via two thermocouples located at the top and bottom levels in the tank's water, using a data-logger. $T_{a 1}, T_{a 2}$ and $T_{a 3}$ (Ambient temperature readings): these temperature readings, represented with their average value $T_{\text {a avg. }}$, were also recorded each 15 minutes via three thermocouples located around the heat pipe testing apparatus.

\subsection{Results of the Heat Pipe Performance with Different Working Fluids}

The purpose made testing apparatus was used in testing the performance of the heat pipes with four different working fluids. As already mentioned, the results from a test using one of the commercially available heat pipes was used as a benchmark in comparing their performance. The working fluids chosen were distilled water, methanol, acetone and ethanol. The experiments were conducted for the purpose of improving or better discovering the effect on the thermal performance and efficiency of the heat pipe, which was recharged with various working fluids at the same filling ratio by infusing always the same amount of working fluid $(10 \mathrm{ml})$.

\subsubsection{Results from the Experiments with the Testing Apparatus for the Heat Pipes}

A summary of the results from testing the performance of the heat pipes with different working fluids appears in Table 2.

Figure 4 displays the behaviour of the temperature rise of the water in the tank of the heat pipe testing apparatus when testing each individual heat pipe, each containing a different fluid. Thus a direct comparison of their performance can be made. 
Alwaer et al., CEST-2018, AIJR Proceedings 4, pp.386-396, 2018

Table 2: The initial and final temperatures of the water, ambient temperature and the efficiency\% of each heat pipe containing a particular working fluid

\begin{tabular}{|c|l|c|c|c|}
\hline & \multicolumn{1}{|c|}{ Description of the test } & $\begin{array}{c}\text { Initial\& final } \\
\text { temp. }{ }^{\circ} \mathrm{C}\end{array}$ & $\begin{array}{c}\text { Ambient temp. avg. } \\
{ }^{\circ} \mathrm{C}\end{array}$ & Efficiency $\%$ \\
\hline 1 & Original heat pipe (Commercial) & $16.2-71.8$ & 21.8 & 57.1 \\
\hline 2 & Heat pipe with Pure water (Working fluid) & $16.3-77.7$ & 19.3 & 63.1 \\
\hline 3 & Heat pipe with Methanol (Working fluid) & $16.4-75.3$ & 19.3 & 60.5 \\
4 & Heat pipe with Acetone (Working fluid) & $16.4-72.5$ & 19.3 & 57.6 \\
5 & Heat pipe with Ethanol (Working fluid) & $16.5-57.7$ & 21.9 & 42.1 \\
\hline
\end{tabular}

The efficiency of each heat pipe, characterised by the working fluid that it contains, is presented for comparison purposes in Figure 5. The addition of the average ambient temperature data during each test enables an enhanced or more informed comparison on the performance of the heat pipes. The ambient temperature plays a major role in the heat loss from the tank of the testing apparatus. This fact affects the heat loss from the water tank and hence affects the water's peak average temperature, reflecting in the heat pipe's efficiency calculation.

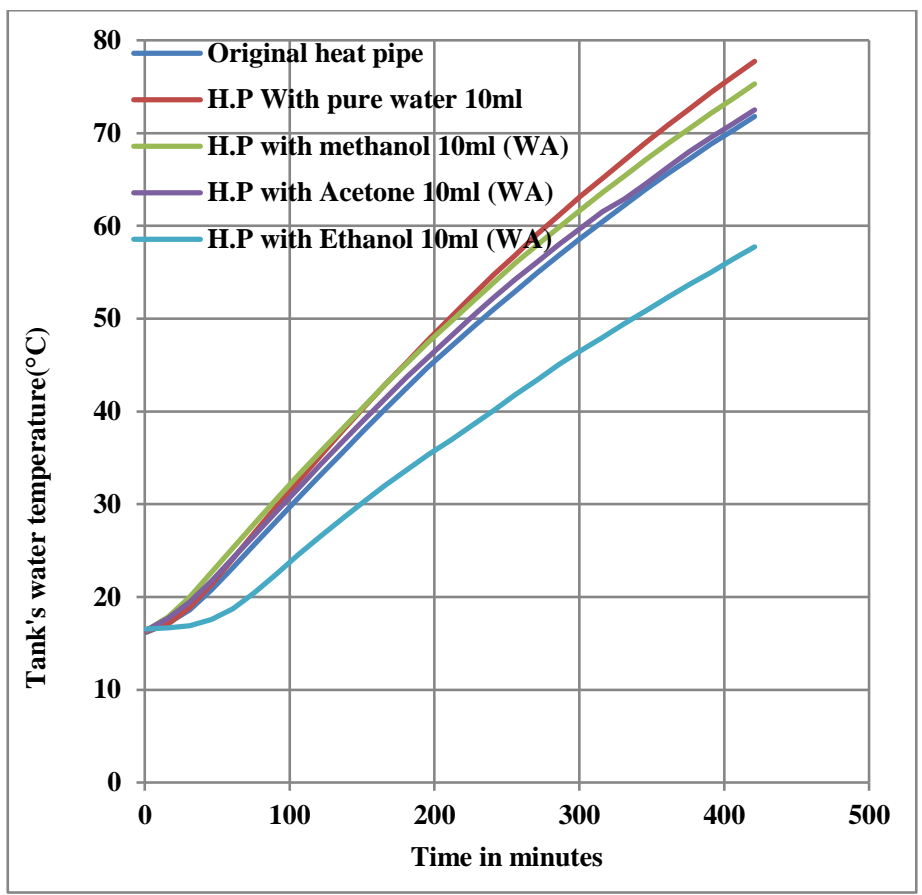

Figure 4: Average water temperature in the tank of the testing apparatus for each heat pipe tested containing a different working fluid 
Thermal Performance of a Heat Pipe with Different Working Fluids

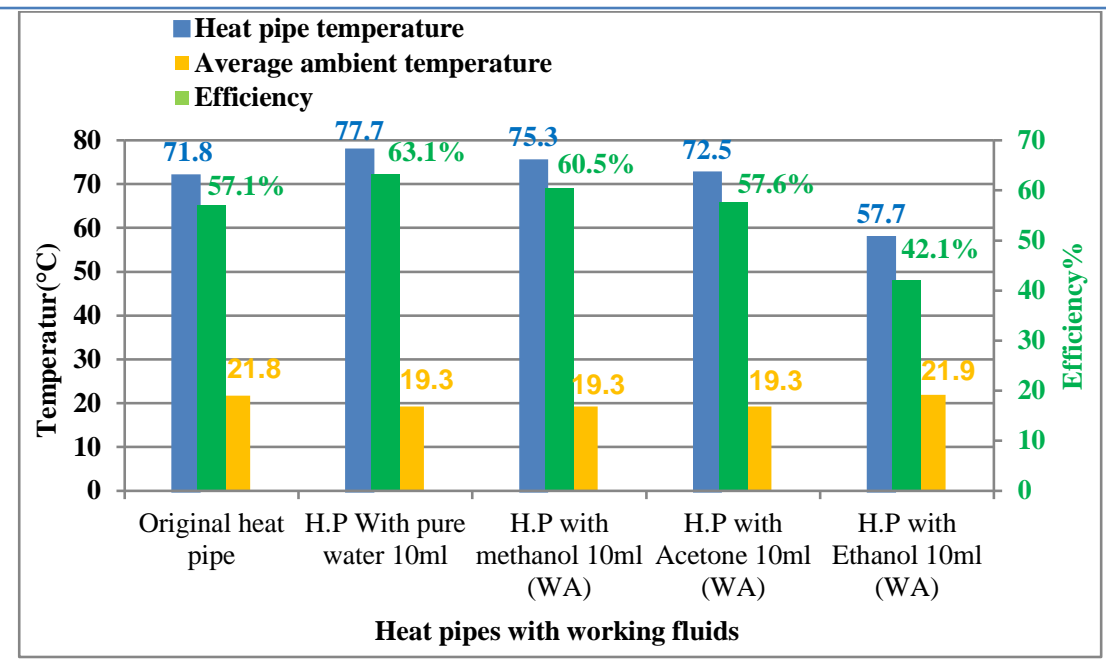

Figure 5: Efficiencies of the heat pipe, bulk water temperatures in the heat pipe testing apparatus tank and average ambient temperatures

\subsubsection{Discussion of results with the testing apparatus for the heat pipes}

The results of the experiments on different working fluids used in the evacuated tube heat pipe have shown that, of all the working fluids chosen in this study, i.e. pure water, methanol, acetone and ethanol, the former three performed well compared to the commercial working fluid.

In terms of ranking their performance, the pure water appeared superior to the others, with a thermal efficiency of $63.1 \%$, followed by Methanol 60.5\%, Acetone 57.6\%, commercial working fluid $57.1 \%$ and Ethanol $42.1 \%$. For a sample calculation of the heat pipe's efficiency in terms of heat transfer to the tank's water see Appendix B.

The averages of ambient temperatures during the tests when using methanol, water and acetone, as working fluids, were equal $\left(19.3{ }^{\circ} \mathrm{C}\right)$, which was colder/.lower than the average of ambient temperatures when testing with the commercial working fluid and ethanol in the heat pipe $\left(21.8{ }^{\circ} \mathrm{C}\right)$, as shown in figure 5 .

It is not expected that such a small change in the ambient temperature would have affected the results significantly because the heat pipe's testing apparatus had a well-insulated tank. The additional heat losses to the environment (had all experiments been performed at the lower ambient temperature of $19.3{ }^{\circ} \mathrm{C}$ ), would be minimal and would have resulted in slightly lowering the efficiencies of the two heat pipes containing the commercial fluid and acetone respectively.

\section{Conclusions}

A totally separate, newly designed and constructed apparatus was used to test the performance of a heat pipe with various "working" fluids. The "commercial working fluid" inside the heat pipe was replaced each time with a different "working" fluid and individual experiments were 
performed. The results of these experiments in terms of the thermal efficiency of the heat pipe were compared as follows:

The heat pipe containing the:

- "Commercial" working fluid - thermal efficiency $57.1 \%$

- "Pure water" - thermal efficiency $63.1 \%$

- "Methanol" - thermal efficiency $60.5 \%$

- "Acetone" - thermal efficiency $57.6 \%$

- "Ethanol" - thermal efficiency $42.1 \%$

From these experiments it is concluded that the thermal efficiency of the heat pipe was improved by $6 \%$ when distilled water was used, as opposed to the commercial working fluid. In the context of the heat pipe being used in an evacuated tube solar energy collector it is expected that such a system will improve its thermal efficiency (compared to the currently commercially available units), with heat pipes containing pure water, methanol or acetone (in this order) as working fluids.

\section{References}

[1] S. Jack \& G. Rockendorf, “Wärmerohre in Sonnenkollektoren- Wärmetechnische Grundlagen und Optimierung sowie neue Ansätze für die Integration,” pp.1-190, November 2013.

[2] H .Barua, M. Ali, M. Nuruzzaman, M. Quamrul Islam \& C. M. Feroz, "Effect of filling ratio on heat transfer characteristics and performance of a closed loop pulsating heat pipe," Procedia Engineering, 56, pp.88-95, 2013.

[3] F. N. Ashok \& K. V. Mali, "Thermal Performance of Thermosyphon Heat Pipe Charged with Binary Mixture," International Journal of Science, Engineering and Technology Research, 4(1), pp.92-102, January 2015.

[4] R. S. Gaugler, "Heat transfer device," U.S., Patent No., 2350348, 6 June 1944.

[5] G. M. Grover, "Evaporation and condensation heat transfer device," U.S., Patent No., 3229759.

[6] G.M. Grover, T.P. Cotter \& G.F. Erickson, "Structures of very high thermal conductance," J. App. Phys., Vol. 35, pp.1190-1191, 1964.

[7] R. S. Gaugler, "Heat transfer device," U.S., Patent No., 2350348, 6 June 1944.

[8] S. M. Peyghambarzadeh, S. Shahpouri, N. Aslanzadeh, \& M. Rahimnejad,"Thermal performance of different working fluids in a dual diameter circular heat pipe,” Ain Shams Eng. J., Apr. 2013.

[9] E. W. Washburn, "International critical tables of numerical data, physics," chemistry and technology. Knoven, 2003.

[10] J. P. Holman, "Heat Transfer," Tenth Edit. USA 2010.

[11] P. Wallin, "Heat Pipe, selection of working fluid," pp. 1-7, 2012.

[12] R. Manimaran, K. Palaniradja, N. Alagumurthi, and J. Hussain, "FACTORS AFFECTING THE THERMAL PERFORMANCE OF HEAT PIPE - A REVIEW,” J. Eng. Res. Stud., III(II), pp.20-24.2012.

[13] D. A. Reay, \& P.A. Kew, "Heat Pipes Theory, Design and Applications," Fifth Edit. 2006. 


\section{Appendixes}

\section{Appendix A}

Typical data collected during the heat pipe tests for the various working fluids.

Testing the heat pipe containing pure water as a working fluid

\begin{tabular}{|c|c|c|c|c|c|c|c|c|}
\hline & Date \&Time & $\begin{array}{l}\mathrm{T}_{1} \text { at } \\
\text { top of } \\
\text { the } \\
\text { tank }\end{array}$ & $\begin{array}{l}\mathrm{T}_{2} \text { at } \\
\text { Bottom } \\
\text { of the } \\
\text { tank }\end{array}$ & Tavg. & $\mathrm{Ta}_{1}$ & $\mathrm{Ta}_{2}$ & $\mathrm{Ta}_{3}$ & $\begin{array}{l}\text { Ta } \\
\text { avg. }\end{array}$ \\
\hline & & $\left({ }^{\circ} \mathrm{C}\right)$ & $\left({ }^{\circ} \mathrm{C}\right)$ & $\left({ }^{\circ} \mathrm{C}\right)$ & $\left({ }^{\circ} \mathrm{C}\right)$ & $\left({ }^{\circ} \mathrm{C}\right)$ & $\left({ }^{\circ} \mathrm{C}\right)$ & $\left({ }^{\circ} \mathrm{C}\right)$ \\
\hline 1 & 09/09/2015 09:01:20:061 & 16.4 & 16.1 & 16.3 & 17.6 & 18.1 & 17.9 & 17.9 \\
\hline 2 & 09/09/2015 09:16:20:046 & 17.9 & 16.2 & 17.1 & 23.4 & 19.7 & 19.0 & 20.7 \\
\hline 3 & 09/09/2015 09:31:20:046 & 20.5 & 17.3 & 18.9 & 24.0 & 20.3 & 19.6 & 21.3 \\
\hline 4 & 09/09/2015 09:46:20:046 & 23.3 & 19.4 & 21.3 & 24.4 & 20.6 & 19.9 & 21.7 \\
\hline 5 & 09/09/2015 10:01:20:046 & 26.3 & 22.0 & 24.1 & 24.8 & 20.9 & 20.2 & 22.0 \\
\hline 6 & 09/09/2015 10:16:20:046 & 29.1 & 24.8 & 27.0 & 24.9 & 21.1 & 20.4 & 22.1 \\
\hline 7 & 09/09/2015 10:31:20:046 & 31.9 & 27.7 & 29.8 & 24.8 & 21.1 & 20.4 & 22.1 \\
\hline 8 & 09/09/2015 10:46:20:046 & 34.5 & 30.4 & 32.5 & 24.9 & 21.1 & 20.4 & 22.2 \\
\hline 9 & 09/09/2015 11:01:20:046 & 37.2 & 33.2 & 35.2 & 24.8 & 21.1 & 20.5 & 22.1 \\
\hline 10 & 09/09/2015 11:16:20:046 & 39.8 & 35.9 & 37.8 & 24.8 & 21.2 & 20.4 & 22.2 \\
\hline 11 & 09/09/2015 11:31:20:046 & 42.3 & 38.5 & 40.4 & 24.8 & 21.2 & 20.4 & 22.2 \\
\hline 12 & 09/09/2015 11:46:20:046 & 44.8 & 41.0 & 42.9 & 24.8 & 21.2 & 20.4 & 22.1 \\
\hline 13 & 09/09/2015 12:01:20:046 & 47.2 & 43.4 & 45.3 & 24.7 & 21.1 & 20.4 & 22.1 \\
\hline 14 & 09/09/2015 12:16:20:046 & 49.7 & 45.9 & 47.8 & 24.7 & 21.1 & 20.3 & 22.1 \\
\hline 15 & 09/09/2015 12:31:20:046 & 52.1 & 48.2 & 50.1 & 24.7 & 21.1 & 20.3 & 22.0 \\
\hline 16 & 09/09/2015 12:46:20:046 & 54.4 & 50.5 & 52.4 & 24.9 & 21.0 & 20.3 & 22.1 \\
\hline 17 & 09/09/2015 13:01:20:046 & 56.8 & 52.7 & 54.8 & 25.0 & 21.0 & 20.2 & 22.1 \\
\hline 18 & 09/09/2015 13:16:20:046 & 58.8 & 54.9 & 56.9 & 25.0 & 21.0 & 20.2 & 22.1 \\
\hline 19 & 09/09/2015 13:31:20:046 & 61.2 & 57.0 & 59.1 & 24.9 & 20.9 & 20.2 & 22.0 \\
\hline 20 & 09/09/2015 13:46:20:046 & 63.2 & 59.1 & 61.1 & 25.0 & 20.9 & 20.2 & 22.0 \\
\hline 21 & 09/09/2015 14:01:20:046 & 65.3 & 61.1 & 63.2 & 24.9 & 20.9 & 20.2 & 22.0 \\
\hline 22 & 09/09/2015 14:16:20:046 & 67.2 & 63.1 & 65.2 & 25.0 & 20.9 & 20.2 & 22.1 \\
\hline 23 & 09/09/2015 14:31:20:046 & 69.2 & 64.9 & 67.1 & 25.2 & 21.0 & 20.3 & 22.2 \\
\hline 24 & 09/09/2015 14:46:20:046 & 71.2 & 66.8 & 69.0 & 25.5 & 21.0 & 20.3 & 22.3 \\
\hline 25 & 09/09/2015 15:01:20:046 & 73.1 & 68.6 & 70.8 & 25.4 & 21.1 & 20.3 & 22.3 \\
\hline 26 & 09/09/2015 15:16:20:046 & 74.9 & 70.4 & 72.6 & 25.4 & 21.1 & 20.4 & 22.3 \\
\hline 27 & 09/09/2015 15:31:20:046 & 76.7 & 72.1 & 74.4 & 25.5 & 21.1 & 20.4 & 22.3 \\
\hline 28 & 09/09/2015 15:46:20:046 & 78.4 & 73.7 & 76.1 & 25.4 & 21.1 & 20.4 & 22.3 \\
\hline 29 & 09/09/2015 16:01:20:046 & 80.1 & 75.4 & 77.7 & 25.4 & 21.1 & 20.4 & 22.3 \\
\hline
\end{tabular}




\section{Appendix B}

Sample calculation of the heat pipe efficiency in terms of heat transfer to the tank's water when the heat pipe containing pure water as the working fluid

The efficiency of the heat pipe is calculated using the following formula, which involves the change of the internal energy of the water contained in the system's tank.

$$
\begin{gathered}
\text { Efficiency }=\frac{\text { Output }}{\text { Input }} \times \mathbf{1 0 0} \% \\
\eta_{h p}=\frac{\left(\Delta Q_{u}\right)}{I \times t} m \times 100 \%
\end{gathered}
$$

Where $\eta_{h p}$ is the heat pipe's efficiency (\%) in terms of heat transfer to the tank's water.

$\Delta Q_{u}(\mathrm{~kJ} / \mathrm{kg})$, is the change in the internal energy of the water in the tester's tank that depends on the temperature $T$ and pressure $P$ of the system.

$t$ is the duration of the time for the test $(7 \mathrm{~h} \mathrm{x} 3600 \mathrm{~h} / \mathrm{s}) ; m(\mathrm{~kg})$, is the mass of the water in the tank and $I(k W)$, is the total solar radiation on the evacuated tube heat pipe, which is the irradiance $\mathrm{R}, \mathrm{kW} / \mathrm{m}^{2}$ from the solar simulator multiplied by the heat pipe's receiving area of $\left(0.08084 \mathrm{~m}^{2}\right)$.

\section{Output}

$$
\begin{aligned}
& \Delta E(k J)=\Delta Q_{u} \times m \\
& \Delta E(k J)=\left(Q_{2}-Q_{1}\right)(k j / \mathrm{kg}) \times m(k g)
\end{aligned}
$$

This sample calculation refers to the case of the heat pipe containing pure water as the working fluid; the initial and final temperatures obtained were 16.3 and $77.7^{\circ} \mathrm{C}$ respectively.

$\Delta E=\left(Q_{77.7}-Q_{16.3}\right) \times m$

Linear interpolation was used to find the energy transferred between the temperatures from a standard table of saturated water.

$\Delta \boldsymbol{E}(\boldsymbol{J})=(325.3192-68.42258) \times 1000 \times 4=\mathbf{1 0 2 7 5 8 6 . 4 8 ~ J}$

\section{Input}

$R=800 \mathrm{~W} / \mathrm{m}^{2}$

Assumed surface area of the evacuated tube heat pipe

$$
\begin{gathered}
=1.72 m(\text { length }) \times 0.047 \mathrm{~m}(\mathrm{dia})=0.08084 \mathrm{~m}^{2} \\
I=800 \mathrm{~W} / \mathrm{m}^{2} \times 0.068 \mathrm{~m}^{2}=\mathbf{6 4 . 6 7 2} \boldsymbol{W} \\
\boldsymbol{t}=\mathbf{7 h} \times \mathbf{3 6 0 0} \boldsymbol{s}=\mathbf{2 5 2 0 0} \boldsymbol{s} \\
\boldsymbol{I} \times \boldsymbol{t}=\mathbf{6 4 . 6 7 2} \boldsymbol{w} \times \mathbf{2 5 2 0 0} \boldsymbol{s}=\mathbf{1 6 2 9 7 3 4 . 4 J} \\
\eta \%=(\mathbf{1 0 2 7 5 8 6 . 4 8} \mathrm{J} / \mathbf{1 6 2 9 7 3 4 . 4 J}) \times 100=\mathbf{6 3 . 1} \%
\end{gathered}
$$

